\title{
Caracterização dos afluentes e efluentes suinícolas em sistemas de crescimento/ terminação e qualificação de seu impacto ambiental
}

\author{
Characterization of affluents and effluents in swine feeding system and environmental \\ impact qualification
}

\author{
Julio Cesar Pascale Palhares ${ }^{\mathrm{I}}$ Maria do Carmo Calijuri ${ }^{\mathrm{II}}$
}

\section{RESUMO}

O objetivo deste trabalho foi caracterizar os afluentes e efluentes de suinoculturas e qualificar o potencial impacto ambiental que estes sistemas de produção poderiam promover nos recursos hídricos. A pesquisa foi realizada em quatro suinoculturas localizadas no município de JaboticabalSP, entre os anos de 2003 e 2004, as quais tiveram seus afluentes $e$ efluentes das instalações e dos sistemas de tratamento analisados mensalmente. Foram coletados os afluentes $e$ efluentes de galpões de crescimento/terminação. O nitrato apresentou concentração máxima de $1.560 \mathrm{mg} \mathrm{L}^{-1}$ de $\mathrm{NO}_{3}-\mathrm{N}$ e o fósforo total de $92 \mathrm{mg} \mathrm{L}^{-1}$ de P. A DQO atingiu uma concentração de $48.300 \mathrm{mg} \mathrm{L}^{-1}$. Todos os sistemas de tratamento de efluentes avaliados apresentaram deficiências técnicas e de manejo. Excetuando-se os parâmetros de temperatura e $\mathrm{pH}$, todos os outros apresentaram-se em valores acima dos estipulados pela legislação para o descarte em corpos d'água superficiais. Intervenções como a melhoria do manejo nutricional, o uso eficiente da água e a correta utilização dos sistemas de tratamento poderiam contribuir para a redução do poder impactante dos efluentes.

Palavras-chave: classificação hídrica, legislação ambiental, recursos hídricos, suínos.

\section{ABSTRACT}

This research work was aimed at characterizing the affluents and effluents and qualifing the environmental impact promoted in the water resources. The research was realized in four swine feeding systems in Jaboticabal-SP, during 2003 and 2004. The affluents and effluents of livestock and treatment systems were analyzed monthly. The nitrate had a maximum concentration of $1.560 \mathrm{mg} \mathrm{L}^{-1} \mathrm{NO}_{3}-\mathrm{N}$ and the total phosphorus was $92 \mathrm{mg} \mathrm{L}^{-1}$ de P. A concentration of $48.300 \mathrm{mg}$ $L^{-1}$ was verified to OCD. Excepting temperature and $\mathrm{pH}$, all parameters showed values up standard legislation to be disposed in superficial water resources. Interventions like the feeding management, the water use, and the best practice in effluent treatment systems could contribute to the reduction in the impact of effluents.

Key words: environmental legislation, swines, water classification, water resources.

\section{INTRODUÇÃO}

A suinocultura é uma das cadeias produtivas que mais se desenvolveu no Brasil nos últimos anos. Através da análise de sua cronologia, percebe-se a importância desta para a economia interna e externa. A ABCS (2006) cita que, há dez anos, o país não figurava entre os países exportadores de maior expressão. Contudo, com o crescimento de cinco vezes em seis anos, o país alcançou o quarto lugar entre os países exportadores. Foram investidos 3,6 bilhões de dólares em investimentos fixos nas granjas brasileiras nos últimos anos, sendo que os números apontam que aproximadamente um milhão de pessoas estejam envolvidas com esta cadeia produtiva.

Paralelamente a estas características gerais, as condições ambientais das granjas também sofreram mudanças, mais por uma pressão legal, a partir da exigência de licenciamentos, do que pelo aumento da conscientização de produtores e agroindústrias. No entanto, desafios ambientais ainda existem, e estes devem ser superados para que a suinocultura continue gerando renda e divisas, mas com equidade ambiental e social.

Considerando os recursos passíveis de impacto pela produção suinícola, os recursos hídricos

\footnotetext{
IEmbrapa Suínos e Aves, CP 21, 89700-000, Concórdia, SC, Brasil. E-mail: palhares@cnpsa.embrapa.br. Autor para correspondência.
} IIDepartamento Hidráulica e Saneamento, Universidade de São Paulo, São Carlos, CP 292, 13560-970, São Carlos, SP, Brasil. 
são os mais afetados devido à própria característica do principal resíduo da produção, que são os dejetos líquidos. OWEN (1994) cita que as emissões poluentes advindas de criações animais são uma preocupação, principalmente, para os suprimentos hídricos, destacando ainda que a produção animal está associada como um dos poluentes de maior potencial poluidor.

De acordo com PALHARES \& JACOB (2002), os resíduos suinícolas que promovem o maior impacto nos recursos hídricos são os dejetos, constituídos basicamente por fezes, urina, restos de ração e água. Outros resíduos que podem causar impacto são as carcaças de animais mortos e as camas.

De acordo com a legislação brasileira, define-se impacto ambiental como qualquer alteração das propriedades físicas, químicas e biológicas do meio ambiente, causada por qualquer forma de matéria ou energia resultante das atividades humanas que, direta ou indiretamente, afetam: I - a saúde, a segurança e o bem-estar da população; II - as atividades sociais e econômicas; III - a biota; IV - as condições estéticas e sanitárias do meio ambiente; V - a qualidade dos recursos ambientais (CONAMA, 1986).

A suinocultura pode causar impacto em todos os setores, atividades e compartimentos citados na legislação, justificando a necessidade de se ter um profundo conhecimento de suas relações com o ambiente. De acordo com a OECD (2003), existem ainda poucos dados disponíveis para determinar a específica contribuição da suinocultura para a poluição das águas.

O objetivo deste trabalho foi caracterizar os afluentes e efluentes de suinoculturas em crescimento/ terminação e qualificar o potencial impacto ambiental que estes sistemas de produção poderiam promover nos recursos hídricos.

\section{MATERIAL E MÉTODOS}

A pesquisa foi realizada em quatro suinoculturas localizadas no município de Jaboticabal$\mathrm{SP}$, as quais tiveram seus afluentes, considerando estes como a água utilizada para higienização das instalações, e efluentes das instalações e dos sistemas de tratamento, quando existentes, analisados mensalmente, pelo período de março de 2003 a março de 2004. Apesar de todas as propriedades monitoradas constituírem-se em sistemas produtivos de Ciclo Completo, somente foram coletados os afluentes e efluentes dos galpões de crescimento/terminação.

Na suinocultura 1 (S1), o afluente constituiuse da água proveniente de um açude localizado a montante do galpão e o efluente foi coletado no cano de descarga da instalação, no momento da lavagem. Esta propriedade possuía um sistema de tratamento constituído por uma lagoa, a qual estava sem manutenção há aproximadamente 5 anos, apresentandose totalmente assoreada por dejetos, o que inviabilizou a coleta do efluente do sistema de tratamento. Somente duas coletas foram realizadas nesta propriedade, pois o proprietário desativou a criação por questões econômicas.

Na suinocultura 2 (S2), o afluente originouse de um poço, sendo as amostras coletadas em uma torneira, a qual abastecia a mangueira de lavagem. $\mathrm{O}$ efluente dos galpões foram coletados em uma caixa de coleta de esgotos, no momento da sua lavagem. A propriedade dispunha de um sistema de tratamento com três lagoas em seqüência, sendo que a amostra de efluente foi coletada sempre no ponto de descarga da primeira lagoa. O motivo para o efluente não ser coletado na terceira lagoa foi devido à não-periodicidade do manejo a partir da segunda lagoa, o que dificultaria a caracterização do efluente. Nesta propriedade, de acordo com relatos dos funcionários, a manutenção do sistema de tratamento era inexistente.

A suinocultura 3 (S3) teve seu afluente captado em um açude que estava povoado com peixes, sendo a amostra coletada em uma caixa d’água. O efluente da criação foi coletado em um escoadouro independente, presente em cada baia, no momento da lavagem. A unidade de tratamento era composta por um peneira para separação da fase sólida da líquida, sendo a amostra de efluente do tratamento constituída desta fase líquida.

Na fazenda denominada suinocultura 4 (S4), a amostra de afluente foi coletada em um poço. $\mathrm{O}$ efluente da criação era diferenciado, pois, nesta propriedade, utilizava-se o manejo de lâmina d’água. A amostra de efluente não proveio da piscina, devido ao seu alto teor de sólidos, mas aguardava-se o seu esvaziamento e posterior lavagem do piso para realizar a amostragem; com isso, o efluente possuía um alto grau de diluição. A propriedade não dispunha de sistema de tratamento, sendo as águas de piscinas e lavagem direcionadas diretamente para um córrego.

As seguintes variáveis de qualidade da água foram utilizadas para a caracterização dos afluentes e efluentes: Temperatura (medição a campo, expressa em ${ }^{0} \mathrm{C}$ ), pH (medição em laboratório, através de peagâmetro de bancada), Oxigênio Dissolvido (OD, determinado pelo Método de Winkler, de acordo com GOLTERMAN et al. (1978), expresso em $\mathrm{mg} \mathrm{L}^{-1}$ ), Compostos Nitrogenados - Nitrato, Nitrito e Amônia (medição em laboratório através de método colorimétrico, empregando-se espectrofotômetro Modelo DR-2000 da 
HACH, expressos em mg L ${ }^{-1}$ ), Fósforo Total (medição em laboratório através de método colorimétrico, empregando-se espectrofotômetro Modelo DR-2000 da $\mathrm{HACH}$, expresso em mg L ${ }^{-1}$ de P), Demanda Bioquímica de Oxigênio (DBO, expresso em $\mathrm{mg} \mathrm{L}^{-1}$ ), Demanda Química de Oxigênio (DQO, medição em laboratório através de método colorimétrico, empregando-se espectrofotômetro Modelo DR-2000 da HACH e bloco digestor para DQO, expresso em $\mathrm{mg} \mathrm{L}^{-1}$ ). Os resultados obtidos com as metodologias empregadas para os compostos nitrogenados, o fósforo total, a DQO e a DBO estão de acordo com o "Standard Methods for the Examination of Water and Wastewater” (1992).

Na qualificação do impacto ambiental, utilizou-se como referencial a Resolução no357 de 17 de março de 2005, do Conselho Nacional de Meio Ambiente (BRASIL, 2005). Nesta Resolução, as águas destinadas à dessedentação de animais devem ter uma qualidade compatível com os padrões de Classe 3.

\section{RESULTADOS E DISCUSSÃO}

Nas duas coletas realizadas em $\mathrm{S} 1$, as variáveis de qualidade da água apresentaram alguns valores acima dos padrões legais. Destacam-se as concentrações de OD, com valores entre 7,1 e 8,3mg L $\mathrm{L}^{-1}$ no afluente e zero em todas as amostras do efluente e do tratamento; as altas concentrações de DQO, atingindo 9.965 $\mathrm{mg} \mathrm{L}^{-1}$ (efluente); as concentrações das formas nitrogenadas muito acima das recomendáveis, assim como as de fósforo. Ressalta-se que, na primeira coleta, para o nitrito e o fósforo, e na segunda coleta, para a amônia, as concentrações observadas foram superiores nas águas do tratamento em relação ao efluente, o que justifica a hipótese da baixa eficiência deste último devido às suas condições de manejo. Apesar de somente duas coletas terem sido realizadas na S1, esta apresentou grande poder impactante na qualidade da água utilizada e potencial poder poluente dos corpos d'água receptores do efluente de seu sistema de tratamento.

Em S2, durante todo o período de coletas, o $\mathrm{pH}$ do afluente apresentou valores ácidos variando de 5,2 a 5,4 (Tabela 1). A acidez das águas do afluente pode estar relacionada aos tipos de rocha e de solo nos quais o poço estava localizado.

As concentrações de OD no afluente variaram de 7,3 a 8,5 $\mathrm{mg} \mathrm{L}^{-1}$, sendo que, no efluente e no tratamento, as concentrações foram nulas para todas as coletas (Tabela 2). Comparando-se os resultados da DBO com os do OD, a situação inverteu-se, pois a DBO do afluente foi praticamente nula e as do efluente e do tratamento muito elevadas, com variações de 186 a 5.601 $\mathrm{m} \mathrm{L}^{-1}$ para o efluente e de 180 a $5.040 \mathrm{mg} \mathrm{L}^{-1}$ no tratamento.

Tabela 1 - Valores de temperatura e pH do afluente (A), efluente (E) e tratamento (T) em S2, S3 e S4.

\begin{tabular}{|c|c|c|c|c|c|c|c|c|c|c|c|c|c|}
\hline & & & & & & & Temp & tura ( & & & & & \\
\hline \multirow{4}{*}{ S2 } & Coleta & fev & mar & $\mathrm{abr}$ & mai & jun & jul & ago & set & out & nov & dez & jan \\
\hline & A & 24 & 23 & 22 & 22 & 23,5 & 22 & 24 & 24,5 & 24,5 & 25 & 23,5 & 24,5 \\
\hline & E & 24 & 23 & 21 & 21 & 21 & 16,5 & 25 & 24,5 & 25 & 25 & 21,5 & 25 \\
\hline & $\mathrm{T}$ & 26 & 25 & 22 & 21 & 21 & 17 & 22 & 25,5 & 25,5 & 26 & 24,5 & 25,5 \\
\hline \multirow{3}{*}{ S3 } & A & 24 & 21 & 22 & 17 & 19 & 16,5 & 21,5 & 25,5 & 26 & 27 & 24 & 27,5 \\
\hline & E & 24 & 23 & 21,5 & 20 & 19 & 16,5 & 22,5 & 27 & 25 & 26,5 & 23,5 & 26,5 \\
\hline & $\mathrm{T}$ & 24 & 23 & 20 & 19 & 18,5 & 14 & 22 & 25 & 24,5 & 25 & 21 & 24,5 \\
\hline \multirow{2}{*}{ S4 } & A & 28,0 & 25,0 & 22,0 & 20,0 & 22,0 & 16,5 & 21 & 24,5 & 25,5 & 25,5 & 25 & 25 \\
\hline & E & 25 & 23,5 & 21,0 & 19,0 & 20,0 & 12,5 & 20,0 & 23,5 & 24,0 & 24,5 & 24 & 23,5 \\
\hline \multicolumn{14}{|c|}{ PH } \\
\hline \multirow{4}{*}{ S2 } & Coleta & fev & mar & abr & mai & jun & jul & ago & set & out & nov & dez & jan \\
\hline & A & 5,3 & 5,2 & 5,3 & 5,3 & 5,2 & 5,4 & 5,3 & 5,2 & 5,3 & 5,3 & 5,3 & 5,4 \\
\hline & E & 7,7 & 7,7 & 7,7 & 7,6 & 6,4 & 8,2 & 8,2 & 7,4 & 6,8 & 7 & 7,2 & 6,2 \\
\hline & $\mathrm{T}$ & 7,1 & 6,9 & 6,9 & 6,9 & 7,3 & 8,1 & 7,2 & 7,1 & 6,9 & 7,1 & 7,2 & 6,7 \\
\hline \multirow{3}{*}{ S3 } & A & 6,5 & 6,5 & 6,6 & 7,2 & 6,8 & 6,9 & 6,9 & 6,9 & 6,9 & 6,8 & 6,7 & 6,8 \\
\hline & E & 8,4 & 7,5 & 7,5 & 6,9 & 8,1 & 7,8 & 7,1 & 7,7 & 8,8 & 7,3 & 7,5 & 8,3 \\
\hline & $\mathrm{T}$ & 7,3 & 8,0 & 8,2 & 8,0 & 7,8 & 8,6 & 8,4 & 8,1 & 7,7 & 7,8 & 8,6 & 8,7 \\
\hline \multirow{2}{*}{ S4 } & A & 6,9 & 6,9 & 7,0 & 6,9 & 6,9 & 6,9 & 6,8 & 7,0 & 6,8 & 6,9 & 6,9 & 6,9 \\
\hline & E & 7,8 & 7,8 & 8,6 & 7,9 & 8,4 & 7,7 & 7,9 & 8,6 & 7,5 & 7,6 & 7,5 & 7,7 \\
\hline
\end{tabular}


Tabela 2 - Valores de oxigênio dissolvido, demanda química de oxigênio e demanda bioquímica de oxigênio do afluente (A), do efluente (E) e do tratamento (T), em S2, S3 e S4.

\begin{tabular}{|c|c|c|c|c|c|c|c|c|c|c|c|c|c|}
\hline \multicolumn{14}{|c|}{ Oxigênio dissolvido (mg/L) } \\
\hline \multirow{4}{*}{$\mathrm{S} 2$} & Coleta & fev & mar & abr & mai & jun & jul & ago & set & out & nov & dez & jan \\
\hline & A & 8,3 & 7,4 & 7,9 & 8,5 & 7,3 & 7,5 & 8,8 & 7,3 & 7,8 & 7,7 & 7,5 & 8,3 \\
\hline & $\mathrm{E}$ & 0 & 0 & 0 & 0 & 0 & 0 & 0 & 0 & 0 & 0 & 0 & 0 \\
\hline & $\mathrm{T}$ & 0 & 0 & 0 & 0 & 0 & 0 & 0 & 0 & 0 & 0 & 0 & 0 \\
\hline \multirow{3}{*}{ S3 } & A & 7,6 & 6,3 & 7,7 & 8,5 & 7,5 & 7,9 & 8,4 & 7 & 7,4 & 6,6 & 6 & 6,5 \\
\hline & $\mathrm{E}$ & 0 & 0 & 0 & 0 & 0 & 0 & 3,3 & 0 & 0 & 0 & 0 & 0 \\
\hline & $\mathrm{T}$ & 0,4 & 0 & 0 & 0 & 0 & 0 & 0 & 0 & 0 & 0 & 0 & 0 \\
\hline \multirow{2}{*}{ S4 } & A & 9,0 & 6,5 & 8,0 & 7,4 & 6,4 & 7,0 & 7,8 & 7,6 & 6,5 & 6,7 & 6,6 & 6,8 \\
\hline & $\mathrm{E}$ & 0 & 0 & 0 & 0 & 0 & 0 & 1,8 & 0 & 4,7 & 0 & 0 & 0 \\
\hline \multicolumn{14}{|c|}{ Demanda química de oxigênio (mg/L) } \\
\hline \multirow{4}{*}{ S2 } & Coleta & fev & mar & abr & mai & jun & jul & ago & set & out & nov & dez & jan \\
\hline & A & 0 & 0 & 0 & 0 & 0 & 0,2 & 0,8 & 0 & 19 & 0 & 1 & 0 \\
\hline & $\mathrm{E}$ & 10630 & 14007 & 40000 & 4250 & 41850 & 48300 & 18300 & 13610 & 17500 & 33224 & 47500 & 13070 \\
\hline & $\mathrm{T}$ & 2280 & 14360 & 39500 & 4600 & 3900 & 15500 & 3810 & 1020 & 1770 & 11580 & 1670 & 16074 \\
\hline \multirow{3}{*}{ S3 } & A & 14,0 & 17,0 & 3,0 & 0,0 & 8,0 & 5,0 & 1,0 & 1,0 & 24,0 & 18 & 0 & 15 \\
\hline & $\mathrm{E}$ & 10610 & 8850 & 15450 & 11100 & 7550 & 26400 & 6650 & 29300 & 18700 & 9230 & 28750 & 14400 \\
\hline & $\mathrm{T}$ & 2376 & 1134 & 4100 & 18050 & 21500 & 16600 & 3090 & 22700 & 12070 & 5760 & 4440 & 5840 \\
\hline \multirow{2}{*}{ S4 } & A & 2,0 & 14,0 & 0,0 & 0,0 & 4,0 & 45,0 & 0 & 0,0 & 14,0 & 0,0 & 0 & 0 \\
\hline & $\mathrm{E}$ & 899 & 9800 & 3050 & 4550 & 5150 & 8150 & 4750 & 1610 & 1810 & 3250 & 2699 & 3366 \\
\hline \multicolumn{14}{|c|}{ Demanda bioquímica de oxigênio (mg/L) } \\
\hline \multirow{4}{*}{$\mathrm{S} 2$} & Coleta & fev & mar & abr & mai & jun & jul & ago & set & out & nov & dez & jan \\
\hline & A & 0 & 0 & 0 & 0 & 0 & 0,2 & 0,8 & 0,1 & 0 & 0 & 0 & 0 \\
\hline & $\mathrm{E}$ & 1253 & 186 & 4536 & 5520 & 4260 & 5100 & 2310 & 2130 & 3540 & 3918 & 5601 & 4920 \\
\hline & $\mathrm{T}$ & 485 & 408 & 780 & 744 & 1080 & 5040 & 2550 & 180 & 1080 & 2280 & 355 & 3420 \\
\hline \multirow{3}{*}{ S3 } & A & 0 & 1,5 & 1,5 & 1,2 & 0 & 1,7 & 1,6 & 2 & 1,6 & 0 & 0 & 0 \\
\hline & $\mathrm{E}$ & 2748 & 324 & 4860 & 2892 & 4536 & 5400 & 2490 & 2100 & 4020 & 2340 & 7448 & 5100 \\
\hline & $\mathrm{T}$ & 848 & 408 & 1680 & 4980 & 4104 & 4980 & 2250 & 2100 & 4080 & 2310 & 1586 & 2640 \\
\hline \multirow{2}{*}{ S4 } & A & 2,7 & 0,0 & 2,0 & 0,0 & 0,0 & 0,1 & 0,3 & 2,1 & 0 & 0 & 0 & 0 \\
\hline & $\mathrm{E}$ & 572 & 408 & 2640 & 2541 & 2106 & 2400 & 492 & 870 & 1152 & 2070 & 1719 & 3660 \\
\hline
\end{tabular}

As concentrações de DQO do efluente demonstram seu alto poder impactante, sendo que, mesmo após a sua passagem pela lagoa de tratamento, altas concentrações de DQO ainda foram observadas, o que não permitiria o despejo deste em nenhum corpo d'água. Esse parâmetro não é padronizado por lei, mas, a partir dos resultados monitorados e do conhecimento em ciências ambientais, pode-se concluir que efluentes com esses valores de DQO seriam altamente impactantes aos recursos hídricos.

A poluição orgânica da água, originada da suinocultura, causa um rápido crescimento de microrganismos, resultando em uma elevada demanda bioquímica de oxigênio; com isso, reduz-se a quantidade de oxigênio disponível para a manutenção da vida aquática. Portanto, a descarga direta em corpos d'água é capaz de causar a morte de peixes pelo aumento da DBO (HOODA et al., 2000).

As concentrações de nitrato, nitrito e amônia são apresentadas na tabela 3. Analisando-se as concentrações desses elementos no efluente e no tratamento, verifica-se que estas apresentaram-se muito acima dos padrões legais, o que inviabilizaria sua disposição na natureza, devido ao elevado impacto causado. No caso do nitrato, a concentração nunca esteve abaixo de $10 \mathrm{mg} \mathrm{L}^{-1}$, que seria o valor máximo 
Tabela 3 - Valores de nitrato, nitrito, amônia e fósforo total do afluente (A), do efluente (E) e do tratamento (T), em S2, S3 e S4.

\begin{tabular}{|c|c|c|c|c|c|c|c|c|c|c|c|c|c|}
\hline \multicolumn{14}{|c|}{ Nitrato $\left(\mathrm{NO}_{3}-\mathrm{N} \mathrm{mg} / \mathrm{L}\right)$} \\
\hline \multirow{4}{*}{ S2 } & Coleta & fev & mar & $\mathrm{abr}$ & mai & jun & jul & ago & set & out & nov & dez & jan \\
\hline & A & 12,0 & 6,2 & 9,7 & 15,0 & 9,2 & 7,0 & 8,4 & 7,9 & 10,5 & 7 & 6,5 & 8,8 \\
\hline & $\mathrm{E}$ & 580 & 200 & 1010 & 740 & 500 & 1510 & 580 & 420 & 620 & 1560 & 739 & 408 \\
\hline & $\mathrm{T}$ & 350 & 51 & 70 & 50 & 60 & 290 & 72 & 20 & 58 & 370 & 40 & 40 \\
\hline \multirow{3}{*}{ S3 } & A & 0,6 & 0,1 & 0,7 & 1,10 & 1,00 & 0,10 & 0,50 & 0,50 & 1,00 & 0,40 & 0,50 & 0,90 \\
\hline & $\mathrm{E}$ & 250 & 270 & 400 & 220 & 80 & 300 & 130 & 870 & 410 & 380 & 460 & 370 \\
\hline & $\mathrm{T}$ & 100 & 110 & 110 & 1210 & 280 & 320 & 80 & 660 & 348 & 170 & 106 & 162 \\
\hline \multirow{2}{*}{ S4 } & A & 0,4 & 0,9 & 0,0 & 0,0 & 0,9 & 0,9 & 0,0 & 0,0 & 2,2 & 0,0 & 0,0 & 0,0 \\
\hline & $\mathrm{E}$ & 160 & 180 & 130 & 80 & 128 & 110 & 98 & 18 & 34 & 560 & 142 & 66 \\
\hline \multicolumn{14}{|c|}{ Nitrito $\left(\mathrm{NO}_{2}-\mathrm{N} \mathrm{mg} / \mathrm{L}\right)$} \\
\hline \multirow{4}{*}{ S2 } & Coleta & fev & mar & $\mathrm{abr}$ & mai & jun & jul & ago & set & out & nov & dez & jan \\
\hline & A & 0,0 & 0,3 & 0,0 & 0,3 & 0,0 & 0,0 & 0,0 & 0,0 & 0,9 & 0,3 & 0,3 & 0,6 \\
\hline & $\mathrm{E}$ & 1050 & 3000 & 2160 & 330 & 690 & 2370 & 960 & 810 & 900 & 1388 & 2400 & 600 \\
\hline & $\mathrm{T}$ & 91 & 120 & 30 & 30 & 108 & 630 & 84 & 60 & 150 & 606 & 96 & 300 \\
\hline \multirow{3}{*}{ S3 } & A & 0,6 & 1,5 & 0,3 & 1,2 & 0,0 & 1,5 & 0,6 & 1,5 & 1,5 & 0,6 & 0,9 & 0,9 \\
\hline & $\mathrm{E}$ & 720 & 990 & 780 & 300 & 90 & 540 & 330 & 1440 & 540 & 504 & 600 & 690,0 \\
\hline & $\mathrm{T}$ & 104 & 300 & 270 & 1050 & 420 & 630 & 144 & 1200 & 510 & 330 & 186 & 210 \\
\hline \multirow{2}{*}{ S4 } & A & 0,0 & 0,3 & 0,6 & 0,6 & 0,0 & 0,6 & 0,3 & 0,6 & 0,0 & 0,0 & 0,0 & 0,0 \\
\hline & $\mathrm{E}$ & 36 & 330 & 180 & 240 & 246 & 420 & 204 & 48 & 72 & 930 & 258 & 132 \\
\hline \multicolumn{14}{|c|}{ Amônia $\left(\mathrm{NH}_{3}-\mathrm{N}\right.$ mg/L) } \\
\hline \multirow{4}{*}{ S2 } & Coleta & fev & mar & $\mathrm{abr}$ & mai & jun & jul & ago & set & out & nov & dez & jan \\
\hline & A & 0,00 & 0,01 & 0,02 & 0,00 & 0,00 & 0,00 & 0,00 & 0,00 & 0,01 & 0,00 & 0,00 & 0,01 \\
\hline & $\mathrm{E}$ & 520 & 1300 & 1150 & 60 & 120 & 520 & 120 & 500 & 240 & 700 & 1280 & 460 \\
\hline & $\mathrm{T}$ & 540 & 400 & 150 & 150 & 588 & 740 & 600 & 250 & 300 & 740 & 660 & 540 \\
\hline \multirow{3}{*}{ S3 } & A & 0,00 & 0,02 & 0,07 & 0,08 & 0,01 & 0,01 & 0,01 & 0,01 & 0,00 & 0,05 & 0,10 & 0,05 \\
\hline & $\mathrm{E}$ & 550 & 340 & 370 & 120 & 360 & 200 & 420 & 760 & 60 & 200 & 200 & 740 \\
\hline & $\mathrm{T}$ & 130 & 220 & 220 & 250 & 331 & 340 & 160 & 700 & 220 & 220 & 380 & 720 \\
\hline \multirow{2}{*}{ S4 } & A & 0,01 & 0,02 & 0,02 & 0,00 & 0,00 & 0,00 & 0,00 & 0,02 & 0,01 & 0,01 & 0,00 & 0,03 \\
\hline & $\mathrm{E}$ & 420 & 400 & 210 & 200 & 300 & 120 & 80 & 160 & 80 & 440 & 230 & 80 \\
\hline \multicolumn{14}{|c|}{ Fósforo Total (mg/L) } \\
\hline \multirow{4}{*}{ S2 } & Coleta & fev & mar & abr & mai & jun & jul & ago & set & out & nov & dez & jan \\
\hline & A & 0,06 & 0,00 & 0,00 & 0,03 & 0,09 & 0,01 & 0,00 & 0,00 & 0,00 & 0,00 & 0,00 & 0,00 \\
\hline & $\mathrm{E}$ & 79 & 71 & 30 & 68 & 86 & 88 & 42 & 13 & 56 & 65 & 117 & 60 \\
\hline & $\mathrm{T}$ & 3,0 & 62 & 30 & 72 & 17 & 66 & 31 & 10 & 15 & 30 & 13 & 11 \\
\hline \multirow{3}{*}{ S3 } & A & 0,01 & 0,03 & 0,00 & 0,03 & 0,10 & 0,00 & 0,00 & 0,00 & 0,00 & 0,00 & 0,00 & 0,03 \\
\hline & $\mathrm{E}$ & 66 & 173 & 18 & 62 & 84 & 63 & 48 & 17 & 50 & 17 & 65 & 64 \\
\hline & $\mathrm{T}$ & 42 & 59 & 8 & 92 & 85 & 65 & 31 & 18 & 16 & 15 & 12 & 14 \\
\hline \multirow{2}{*}{ S4 } & A & 0,0 & 0,1 & 0,1 & 0,1 & 0,1 & 0,0 & 0,0 & 0,1 & 0,1 & 0,1 & 0,1 & 0,1 \\
\hline & $\mathrm{E}$ & 77 & 69 & 41 & 47 & 17 & 25 & 15 & 11 & 12 & 81 & 37 & 13,0 \\
\hline
\end{tabular}

Ciência Rural, v.37, n.2, mar-abr, 2007. 
permitido pela Resolução no 357/05, sendo que, acima deste valor, há risco para a saúde humana, a animal e a ambiental.

O íon amônio pode estar presente na água ou no solo devido à degradação dos compostos orgânicos nitrogenados, bem como em decorrência da redução do nitrato. Concentrações consideráveis deste íon são detectadas em águas residuárias (acima de 50 $\left.\mathrm{mg} \mathrm{L}^{-1}\right)$ (RUMP \& KRIST, 1992).

O fósforo total apresentou concentrações mínimas de zero e máximas de $117 \mathrm{mg} \mathrm{L}^{-1}$ (Tabela 3). Estas elevadas concentrações determinam o alto poder eutrofizante desses efluentes. A Resolução nº 357/05 determina uma concentração máxima de $0,075 \mathrm{mg} \mathrm{L}^{-1}$ de $\mathrm{P}$ para rios. Pelas concentrações de fósforo avaliadas no efluente e no tratamento, conclui-se que, caso estas águas fossem despejadas no ambiente, o impacto proporcionado seria muito grande, além do elevado impacto causado na qualidade da água do afluente. Com isso, apesar de ter ocorrido uma remoção do fósforo no sistema de tratamento, suas concentrações ainda apresentaram-se elevadas, indicando que medidas devam ser tomadas para o aumento da eficiência na remoção deste elemento, já que a porcentagem média desta eficiência foi de $51 \%$ (PALHARES \& CALIJURI, 2001).

Avaliando-se a S2, pôde-se concluir que o impacto nos recursos hídricos por ela utilizados foi muito acentuado, pois, a partir de uma água de excelentes características qualitativas, gerou-se um efluente e, posteriormente, uma água de tratamento totalmente descartados para usos nobres, para os quais este afluente poderia ser utilizado.

Tomando-se como referencial somente as variáveis de temperatura e $\mathrm{pH}$ como parâmetros para avaliação do impacto, conclui-se que a S3 não provocou qualquer impacto, pois ambos os valores mensurados no efluente e no tratamento apresentaramse próximos aos do afluente, com valores de $\mathrm{pH}$ próximos a neutralidade (Tabela 1).

Considerando-se o que a Resolução nº 357/ 05 estabelece e analisando-se as concentrações dos parâmetros no afluente, nota-se que, para o nitrato, os valores mantiveram-se dentro do padrão, mas o nitrito atingiu o valor de $1,5 \mathrm{mg} \mathrm{L}^{-1}$. Este poder poluente do afluente deveu-se a ser ele originário de uma água residuária, onde ocorreu o aporte de matéria orgânica, seja através dos dejetos dos peixes e/ou dos restos de ração.

Como verificado nos outros sistemas, o impacto em relação ao OD do afluente foi elevado, pois, a partir de altas concentrações do gás nesta água, foram obtidas águas com concentrações nulas na maior parte das coletas, tanto no efluente como no tratamento esta ausência do gás condiciona elevadas concentrações de DBO e DQO (Tabela 2).

As concentrações de nitrato, nitrito e amônia na S3 sempre apresentaram-se acima dos padrões legais (Tabela 3). Estes constituem-se em elementos tóxicos para a saúde humana e a animal e a qualidade ambiental; portanto, medidas mitigatórias deveriam ser conduzidas para reduzir o impacto desta atividade produtiva da propriedade. PIMENTEL (1996) explica que o nitrato não é tóxico, mas sim o nitrito gerado de sua reação, o qual passa para a corrente sanguínea e promove a complexação do ferro da hemoglobina, impedindo, assim, o transporte de oxigênio para o sangue. Animais jovens, ingerindo $\mathrm{N}$ em concentrações de $5 \mathrm{mg} \mathrm{l}^{-1}$ de $\mathrm{N}^{-\mathrm{NO}_{3}}$ na água que bebem, podem desenvolver a doença da matahemoglobinemia.

A concentração de fósforo total variou de 17 a $173 \mathrm{mg} \mathrm{L}^{-1}$ no efluente e de 8 a $92 \mathrm{mg} \mathrm{L}^{-1}$ no tratamento (Tabela 3). Assim, apesar de o afluente da S3 já ser proveniente de um uso zootécnico, a suinocultura causou impacto na qualidade da água utilizada para a higienização das instalações. Como ocorrido para os elementos nitrogenados em quatro coletas, as concentrações do tratamento foram superiores às do efluente, sendo a eficiência do sistema de tratamento de 54\%. Não houve correlação entre as máximas e mínimas concentrações em ambas as águas.

Em duas coletas, o OD esteve presente nas águas do efluente da S4 com concentrações de 1,8 e $4,7 \mathrm{mg} \mathrm{L}^{-1}$, sendo que, no restante, a concentração foi sempre nula (Tabela 2). A razão para a presença do gás pode ser devida ao fato de que, especificamente nestas coletas, o efluente estava mais diluído, aumentando com isto a possibilidade da presença do oxigênio na amostra.

As concentrações de DBO e DQO na S4 são apresentadas na tabela 2. As diferenças nas concentrações de DBO e DQO da S4, em relação às da S2 e S3, são decorrência da diferença nos sistemas de lavagem das baias, pois os dejetos da S4 apresentaramse com um grau de diluição muito maior devido ao uso das piscinas

As concentrações dos compostos nitrogenados em S4 se apresentaram elevadas (Tabela 3), e, considerando que nesta propriedade não havia nenhum sistema de tratamento, a condução deste efluente pelo solo e sua disposição nos rios provocaria impactos em diversos recursos naturais. A maior parte da amônia presente na urina dos animais pode ser oxidada a nitrato a partir do processo de nitrificação. Este processo pode ocorrer nos solos devido ao uso 
dos dejetos como adubo, aumentando o risco de contaminação das águas subterrâneas por nitrato (CLOSE et al., 2001).

O fósforo total no afluente apresentou-se com concentrações de 0,0 a $0,1 \mathrm{mg} \mathrm{L}^{-1}$ e, no efluente, entre 11 e 81 $\mathrm{mg} \mathrm{L}^{-1}$ (Tabela 3), configurando o impacto na qualidade da água.

Entre os principais componentes poluentes dos dejetos suínos estão o nitrogênio e o fósforo. Em vários rios europeus, o nitrogênio dos dejetos animais contribuíram com 40 a $60 \%$ do nitrogênio total encontrado. $\mathrm{O}$ excesso desses elementos, assim como de outros, pode favorecer a eutrofização do meio e conseqüente desenvolvimento desordenado de algas (PENZ JUNIOR, 2000).

As menores concentrações em S4 avaliadas para todas as variáveis, comparando-se esta com a S2 e a S3, não devem ser motivo para concluir que esta foi menos impactante que as outras duas, pois essas baixas concentrações foram resultado da coleta de um efluente diferenciado. Caso opte-se por coletar a primeira água da $\mathrm{S} 4$, ou seja, aquela proveniente da piscina, certamente as concentrações poderiam ser iguais ou maiores que as encontradas para as outras duas criações.

A caracterização dos efluentes das suinoculturas monitoradas apresentaram como resultado comum a não-conformidade destes com os padrões estipulados pela legislação hídrica vigente. Portanto, algumas ações podem ser implementadas para minimizar o poder impactante desses efluentes e aumentar a eficiência dos sistemas de tratamento. Ressalta-se que essas ações devem ter um caráter sistêmico, pois a qualidade de um efluente é determinada pelo manejo no interior da granja.

As ações propostas incluem: alterar o manejo nutricional das granjas, optando-se pela alimentação em fases, com separação de sexos e utilizando-se ferramentas nutricionais como o balanceamento das rações por aminoácidos essenciais e o uso de fitase; verificar a estrutura de condução hídrica nas instalações, pautando-se pela utilização de bebedouros eficientes no uso da água, pela troca de mangueiras de condução por encanamentos de PVC e pelo monitoramento contínuo de vazamentos; avaliar as estruturas construídas, principalmente, quanto à entrada das águas das chuvas nas canaletas de condução de dejetos e ás drenagens dos terrenos onde estão localizados os sistemas de tratamento, impedindo a entrada dessas águas nesses sistemas; alterar os sistemas de lavagem de pisos, realizando a barragem somente na saída dos lotes, sendo a raspagem diária uma prática, utilizando-se equipamentos de pressão para realizar a lavagem; alterar e/ou aumentar a eficiência dos sistemas de tratamento existentes, pois estes se mostraram ineficientes quanto ao atendimento das exigências legais.

\section{CONCLUSÕES}

Excetuando-se a temperatura e o $\mathrm{pH}$, todos as outras variáveis apresentaram valores acima dos estipulados pela legislação (Resolução no 357/05 do Conama), para o descarte em corpos d'água superficiais.

A partir dos resultados obtidos nas amostras de efluentes e descartes dos sistemas de tratamento, condicionando a elevadas demandas químicas e bioquímicas de oxigênio e a altas concentrações das formas nitrogenadas e de fósforo total, para o descarte em ambientes lóticos, pode-se concluir que os resultados obtidos com essas variáveis proporcionaram o atingimento do objetivo proposto por este trabalho, que era o de qualificar o potencial impacto ambiental que esses sistemas de produção poderiam promover nos recursos hídricos superficiais.

Estes resultados poderão servir como referencial técnico em avaliações de impacto ambiental pela suinocultura, sendo essa avaliação uma etapa obrigatória em um processo de licenciamento ambiental da atividade. Além disso, estes dados poderão auxiliar no delineamento de políticas públicas voltadas para as regiões de concentração suinícola.

\section{REFERÊNCIAS}

ASSOCIAÇÃO BRASILEIRA DOS CRIADORES DE SUÍNOS - ABCS. ABCS: posicionamento estratégico. Brasília: ABCS, 2006. 35p.

BRASIL. CONSELHO NACIONAL DE MEIO AMBIENTE. Resolução n 357 de 18 de março de 2005. Dispõe sobre uma nova classificação para as águas doces, bem como para as águas salobras e salinas do território nacional. Acesso em: 01 de abr, 2005. On line. Disponível em http// :www.mma.gov./conama.

CONSELHO NACIONAL DE MEIO AMBIENTE. Resolução n. 01 de 23 de janeiro de 1986. Dispõe sobre a Política Nacional de Meio Ambiente. Acesso em: 25 de jan. de 2004. On line. Disponível em: http//:www.mma.gov.br.

CLOSE, M.E. et al. Fate and transport of nitrate and pesticides in New Zealand's aquifers. In: ROSEN, M.R.; WHITE, P.A. Groundwaters of New Zealand. Wellington: NZ Hidrological Society, 2001. p.185-220.

GOLTERMAN, H.L. et al. Methods for physical and chemical analysis of freshwaters. London: Blackweed, 1978. 214p.

HOODA, P. et al. A Review of water quality concerns in livestock areas. The Science of the Total Environment, v.250, n.1-3, p.143-167, 2000. 
ORGANIZATION FOR ECONOMIC CO-OPERATION AND DEVELOPMENT - OECD. Agricultura: trade and environment. The pig sector. Paris: OECD, 2003. 187p.

OWEN, J.B. Pollution in livestock production systems: an overview. In: DEWI, I.A. et al. Pollution in livestock production systems. London: Cab International, 1994. p.115.

PALHARES, J.C.P.; JACOB, A.D. Impacto ambiental da suinocultura e da avicultura nos recursos hídricos. In: SIMPÓSIO SOBRE MANEJO E NUTRIÇÃO DE AVES E SUÍNOS E TECNOLOGIA DE PRODUÇÃO DE RAÇÕES, 2002, Campinas. Anais... Campinas: CBNA, 2002. p.31-44.

PALHARES, J.C.P.; CALIJURI, M.C. Avaliação do impacto de criações animais na qualidade dos recursos hídricos do município de Jaboticabal (SP): subsídio para sensibilização ambiental dos produtores rurais. 2001. 135f. Tese (Doutorado em Engenharia Ambiental) - Escola de Engenharia de São Carlos, Universidade de São Paulo, São Carlos.

PENZ JUNIOR, A.M. A influência da nutrição na preservação do meio ambiente. 2000. Acesso em: 28 de set. de 2000. On line. Disponível em: http:// www.ecolatina.com.br.

PIMENTEL, D. Green revolution agriculture and chemical hazards. Science of the Total Environment. v.188, n.1, p.586-598, 1996.

RUMP, H.H.; KRIST, H. Laboratory manual for examination of water, wastewater, and soil. New York: VCH, 1992. 190p.

STANDARD METHODS FOR THE EXAMINATION OF WATER AND WASTEWATER. Washington: American Public Health Association, 1992. 619p. 